controlled diabetes at the time of Ramadan. The most likely reason is the generally low expectation in standard of control in many of these patients, who experience wide fluctuations of blood sugar during the rest of the year, who are rarely assiduous in urine testing, and who perhaps expect a degree of malaise in Ramadan anyway. Further studies are under way to examine this.

In general, we feel it appropriate that Muslims who have diabetes mellitus should be advised not to fast during Ramadan, unless their diabetes is controlled on diet alone. Those patients who elect to fast and who require insulin should understand that the insulin should be omitted in the morning and a suitable dose given in the evening. Ketosis-prone insulin-requiring patients should be particularly advised to avoid fasting. Patients on oral hypoglycaemic agents may need to reduce the dose of their tablets, should seek personal medical advice, and should pay particular attention to their diabetic control during Ramadan.

$S$ G BARBER

SEBASTIAN FAIRWEATHER

A D WRIGHT

$M$ G FitzGerALD

J M MALINS

The General Hospital,

Analgesia in terminal malignant disease

SIR,-The letter by Dr P S B Russell (9 June, $p$ 1561) draws attention to the difficulty of controlling symptoms in cases of advanced malignancy when oral medication is no longer possible. There are three very important reasons why injections should be avoided whenever possible. The first and most important one from the patient's point of view is that injections are painful-the more so when patients are cachectic and bed-bound so that the buttocks cannot be used. Moreover, in many such patients lymphoedema restricts the areas available. The other two reasons have been highlighted by Vere ${ }^{1}$ : he has shown that by intramuscular injection it is difficult to obtain adequate analgesia without the plasma level of the analgesic reaching the level at which side effects occur, and also that the plasma level of the analgesic falls quickly so that only a short period of analgesia is obtained.

The attention of one of us (JK) was drawn to the advantages of oxycodone pectinate (Proladone) suppositories by the case of a nurse who had self-administered 12 such suppositories in an attempt at suicide but had merely slept quietly and with no serious respiratory depression for 24 hours, making an uneventful recovery. We started using this on our patients with a pain problem with very satisfactory results-obtaining at least six and often eight hours' analgesia with no side effects. Proladone was temporarily withdrawn from the market but suppositories of oxycodone pectinate $30 \mathrm{mg}$ are now available on NHS prescriptions.

Encouraged by the clinical success of this method we explored the use of other medication by suppository. We now frequently use prochlorperazine, $25 \mathrm{mg}$ 8-hourly, or chlorpromazine, $100 \mathrm{mg}$ 8-hourly, for vomiting and aminophylline, $360 \mathrm{mg} \mathrm{8-12-hourly,} \mathrm{for} \mathrm{"wet}$ lungs." Suppositories of indomethacin $100 \mathrm{mg}$ are very useful in controlling the pain of bony metastases as well as the pain of osteoarthritis.
A suppository given at night often means that the patient wakes in the morning without pain. Recently we have been using diazepam by suppository. Although these suppositories are available on the Continent they are not yet commercially available in this country. But a helpful pharmacist will usually oblige-all that is required is to crush a 5 or $10 \mathrm{mg}$ tablet, mix it thoroughly with warmed cocoa butter, and pour it into a mould. If kept in a cool place these have a shelf life of many months. In one case we found it possible to control all the symptoms of an advanced cerebral tumour by the use of a suppository of $10 \mathrm{mg}$ diazepam 8-hourly with no other medication. The patient was rousable for toilet and feeding purposes but otherwise slept quietly. Suppositories of diazepam we are finding very helpful in the control of muscle spasm associated with some spinal cord lesions, as well as being a useful sedative in tense patients.

F R GUSTERSON J KAY

St Barnabas' Home,

Worthing, West Sussex BN13 2QF

${ }^{1}$ Royal College of Physicians of London, Topics in
Therapeutics, No 4, ed D W Vere. Tunbridge Therapeutics, No 4, ed $\mathrm{D} W$ Vere. Tunbridge
Wells, Pitman Medical Publishing Company, 1978.

SIR,-We were interested to read the article by Drs $C$ Drinkwater and $R G$ Twycross (5 May, p 1201) and the letter from Dr P S B Russell (9 June, $p$ 1561) regarding pain relief in terminal malignant disease. We also use a four-hourly narcotic (diamorphine) in chloroform water instead of Brompton mixture.

For those patients who cannot swallow or where gastric absorption is impaired we find that sublingual phenazocine (Narphen) is a very satisfactory substitute: $5-20 \mathrm{mg}$ provides strong analgesia for up to six hours. This avoids injections and the relative lack of sedation may allow active life to continue for longer than may be possible if the patient has to carry an infusion pump (however miniaturised). For those who have a dry mouth or dislike the taste morphine suppositories provide an alternative.

We believe that injections or infusions should be only a last resort and non-invasive methods of administration should be tried first. If drug-induced vomiting becomes a problem our experience suggests that haloperidol is superior to the phenothiazines and in low doses $(0.5 \mathrm{mg}$ orally two or three times a day) will suppress nausea and vomiting without the sedation which accompanies regular phenothiazine administration.

I M C CLARKE $S M$ TEMPEST

Pain Relief Service, Leeds General Infirmary Leeds LS1 3EX

\section{The why and how of hypnotic drugs}

SIR,-The review on hypnotic drugs by Professor Ian Oswald (5 May, p 1167) once again reminds us of the cumulative effects of hypnotics, especially the benzodiazepines.

As a pharmacist in the United States, I dispense thousands of doses of benzodiazepines per month and I have often wondered just how much thought physicians give to the adverse effects of these drugs. There was one statement in Professor Oswald's review that bothered me, however, and that was "as a psychiatrist I see only the rarest justification for their (benzodiazepines) daytime use, except to enable the doctor to feel he is not being inactive." It must be presumed from this that a doctor might prescribe this medication to make the doctor feel as if he is doing something for the patient. If this is the case, and I surely hope not, then please for safety's sake write for a placebo. It is understandable that many physicians are under pressure from their patients to produce results. However, unnecessary pharmacotherapy with sedatives or any other chemical is a dangerous game which involves the other health professionals as unwilling players.

KENNETH L THOMPSON

Hampton General Hospital

Hampton, Virginia 23669, USA

\section{Colour coding of insulins}

SIR,-Colour coding has been used on insulin pack and label for many years in the UK to identify the strengths (mainly 40 and 80 units $/ \mathrm{ml}$ ) and the types of insulin preparations. The familiar blue and green backgrounds for $40 \mathrm{U} / \mathrm{ml}$ and $80 \mathrm{U} / \mathrm{ml}$ strengths respectively have been useful checks; but the colourcoding device for type has become extremely complex. Not only has it had to incorporate 18 different insulin preparations but it also, in recent years, has had to contend with different degrees of purification. More and more, insulins have come to be identified by brand name.

With the replacement of the 40 and 80 strengths by a single $100 \mathrm{U} / \mathrm{ml}$ strength in prospect and the likely extension of insulin purification, the Medical Advisory Committee and the Medical and Scientific Committee of the British Diabetic Association had already held preparatory meetings with the insulin manufacturers and other involved bodies. It was proposed to make these changes along with standardised simplified labelling in a single planned operation. As a consequence of Novo's decision to bring its insulin pack and label designs in the UK into line with its practices elsewhere, we called a special meeting to decide how the new situation could most safely be met. The recommendations published by $\mathrm{Mr} \mathrm{J}$ Mellowes in his letters to the $B M \mathcal{Y}$ (2 June, $p$ 1488) and the Pharmaceutical fournal (26 May) and appearing as an annotation in the Lancet (26 May) were the conclusions arrived at by that meeting. Individual pharmaceutical companies are, of course, entirely free, within the limits imposed by statutory regulations, to decide on such matters as pack design, use of colour, and so on for themselves. The British Diabetic Association has always acted as a common meeting ground for the many interests and bodies involved in the care of the diabetic and agreement has been on a voluntary basis. The pharmaceutical firms, Novo not least among them, have given much support to the medical, scientific, and welfare functions of the association, for which it is grateful. It is greatly to be hoped that this fruitful cooperation will continue.

Until some uniform format for insulin packaging is agreed, insulin-taking diabetics and all those concerned with their treatment are advised to check carefully the type and strength of insulin prescribed from the 